\title{
Preparation of Poly(acrylic acid-acrylamide/starch) Composite and Its Adsorption Properties for Mercury (II)
}

\author{
Wenjuan Zhu ${ }^{1, *}$, Zhiyong Yang ${ }^{1}$, Akram Yasin ${ }^{2}$, Yanxia Liu ${ }^{2}$ and Letao Zhang ${ }^{1}$ \\ 1 School of Chemical and Environmental Engineering, Xinjiang University of Engineering, Urumqi 830026, \\ China; yzy11518602@163.com (Z.Y.); zhanglt@ms.xjb.ac.cn (L.Z.) \\ 2 Xinjiang Technical Institute of Physics and Chemistry, Chinese Academy of Sciences, Urumqi 830011, China; \\ akram@ms.xjb.ac.cn (A.Y.); liuyanxia@ms.xjb.ac.cn (Y.L.) \\ * Correspondence: zhuwenjuan100@126.com
}

check for updates

Citation: Zhu, W.; Yang, Z.; Yasin, A.; Liu, Y.; Zhang, L. Preparation of Poly(acrylic acid-acrylamide/starch) Composite and Its Adsorption Properties for Mercury (II). Materials 2021, 14, 3277. https://doi.org/ $10.3390 /$ ma14123277

Academic Editor: Cristina Della Pina

Received: 30 April 2021

Accepted: 9 June 2021

Published: 14 June 2021

Publisher's Note: MDPI stays neutral with regard to jurisdictional claims in published maps and institutional affiliations.

Copyright: (c) 2021 by the authors. Licensee MDPI, Basel, Switzerland. This article is an open access article distributed under the terms and conditions of the Creative Commons Attribution (CC BY) license (https:// creativecommons.org/licenses/by/ $4.0 /)$.

\begin{abstract}
The poly(acrylic acid-acrylamide/starch) composite was synthesized by solution polymerization, aiming to adsorb mercury (II) in water. The resulted copolymer was characterized by particle size exclusion chromatography (SEC), Fourier transform infrared spectroscopy (FTIR), thermogravimetry (TG), scanning electron microscopy (SEM) and dynamic light scattering particle size analyzer (DLS). It turned out that starch was successfully incorporated with the macromolecular polymer matrix and played a key role for improving the performance of the composites. These characterization results showed that the graft copolymer exhibited narrow molecular weight distribution, rough but uniform morphology, good thermal stability and narrow particle size distribution. The graft copolymer was used to remove $\mathrm{Hg}$ (II) ions from aqueous solution. The effects of contact time, $\mathrm{pH}$ value, initial mercury (II) concentration and temperature on the adsorption capacity of $\mathrm{Hg}$ (II) ions were researched. It was found that after $120 \mathrm{~min}$ of interaction, poly(acrylic acid-acrylamide/starch) composite achieved the maximum adsorption capacity of $19.23 \mathrm{mg} \cdot \mathrm{g}^{-1}$ to $\mathrm{Hg}$ (II) ions with initial concentration of $15 \mathrm{mg} \cdot \mathrm{L}^{-1}, \mathrm{pH}$ of 5.5 at $45^{\circ} \mathrm{C}$. Compared with other studies with the same purpose, the composites synthesized in this study present high adsorption properties for $\mathrm{Hg}$ (II) ion in dilute solution. The adsorption kinetics of $\mathrm{Hg}$ (II) on the poly(acrylic acid-acrylamide/starch) composite fits well with the pseudo second order model.
\end{abstract}

Keywords: composite; starch; acrylic acid; acrylamide; adsorption

\section{Introduction}

Starch is a kind of natural and renewable macromolecule carbohydrate, which has the characteristics of broad obtaining source, low cost, good biodegradability and no secondary pollution [1,2]. Therefore, modified starch adsorbent has become a research hotspot in removing pollutants from water [3-5]. Starch does not have good water resistance and processability. It can be graft-copolymerized with vinyl carboxylic acid monomer to make composite materials to enhance its swelling, water resistance and adsorption properties, expanding the application of starch in the functional material field. Starch based copolymer adsorbents have been studied for many years, but most of the composite materials with high adsorption performance are aiming at high concentration of metal ion solution [6,7]. In this study, a starch-based adsorbent with superior adsorption capacity for low concentration mercury (II) ions was synthesized. The material exhibits narrow molecular weight distribution, good thermal stability and uniform surface morphology.

In recent decades, heavy metal pollution in water environment has attracted widespread attention, especially mercury ion pollution, which is the most toxic [8]. Due to the characteristics of persistence and bioaccumulation, the ingestion of mercury ions will cause serious damage to human body and organisms $[9,10]$. $\mathrm{Hg}$ (II) ions can form $\mathrm{Hg}$-S bonds with cysteine of protein chain, which can cause damage to central nervous system, cardiovascular system, kidney and bone [11]. Therefore, it is of great significance to remove 
mercury (II) ions in aqueous solution for the protection of ecological environment and human health [12,13]. Mercury (II) ions in the environment mainly come from chlor alkali, battery manufacturing, chemical fertilizer, paper making, plastics, refining and paint industries $[14,15]$. The methods of mercury removal in water include chemical precipitation, coagulation, ion exchange, membrane filtration and adsorption [16,17]. Since most adsorption processes are exothermic and spontaneous. Adsorption is the most common method for removing mercury ions from water. Although the adsorption capacity of activated carbon is very strong, high production cost and poor selectivity limit its extensive usage $[18,19]$. As a result, the adsorbent composite that can remove $\mathrm{Hg}$ (II) ions in water have attracted great interest $[20,21]$. In practice, there are not many cases of high concentration mercury ion contamination. According to the comprehensive sewage discharge standard GB8978-2005 in China, the concentration of mercury ions in the discharged sewage shall not exceed $0.05 \mathrm{mg} \cdot \mathrm{L}^{-1}$ [22]. In this study, a composite material for treating lower concentrations of mercury ions was synthesized in order to further investigate the ability of the material to deal with actual mercury ion wastewater.

\section{Materials and Methods}

\subsection{Materials}

Acrylic acid (AA) was distilled under reduced pressure to eliminate the inhibitor. Acrylamide (AM) was purified by recrystallization from benzene. Potassium persulfate (KPS) was recrystallized from water. N, N-methylenebisacrylamide (MBA), sodium hydroxide $(\mathrm{NaOH})$, mercuric chloride $\left(\mathrm{HgCl}_{2}\right)$ and methanol were of analytical grade and used as received. These chemicals were supplied by Tianjin Chemical Reagent Factory, Tianjin, China. Starch was purchased from JinHui Corn Products, Binzhou, Shandong, China.

\subsection{Synthesis of PAA-AM/St Superabsorbent Composite}

PAA-AM/St composite was prepared as follows: For a typical experiment, $12 \mathrm{~mL}$ AA was neutralized with $8 \mathrm{M}$ sodium hydroxide solution in an ice bath under stirring. Then this neutralized AA and $10.0 \mathrm{~g}$ AM were added to $80 \mathrm{~mL}$ distilled water in $250 \mathrm{~mL}$ four-neck flask assembled with a reflux condenser, a thermometer and a $\mathrm{N}_{2}$ inlet tube. Then $0.15 \mathrm{~g}$ of MBA was added, the mixture was magnetically stirred for $30 \mathrm{~min}$ before $2.0 \mathrm{~g}$ of starch were added. After the starch was evenly dispersed, the mixture was heated to $70{ }^{\circ} \mathrm{C}$ gradually while $0.12 \mathrm{~g}$ of KPS was added. The polymerization reaction was continued for additional $30 \mathrm{~min}$ at $70{ }^{\circ} \mathrm{C}$. The whole process was under the protection of nitrogen atmosphere. The resulting granular product was placed in Soxhlet extractor, washed and purified with the mixture of methanol and water (6:1 by volume), dried at $65^{\circ} \mathrm{C}$ for $48 \mathrm{~h}$ in a vacuum oven. All samples were milled and screened into particles with size of 40-80 mesh for further tests. The PAA-AM/St composite was obtained.

\subsection{Characterization}

The molecular weight and the molecular weight distribution analysis of PAA-AM/St were carried out by Waters e2695 size exclusion chromatography (SEC) (Water Pvt. Ltd., Milford, MA, USA), equipped with waters 2414 differential detector and $6.0 \mathrm{~mm} \times 150 \mathrm{~mm}$ HSPgel $^{\mathrm{TM}}$ column [23]. The flow rate was fixed at $0.5 \mathrm{~mL} \mathrm{~min}^{-1}$ under $30^{\circ} \mathrm{C}$. Dextran and sodium polystyrene sulfonate were used as standard 3450 polymers [24]. The FTIR spectra of raw starch and PAA-AM/starch composite were measured by a DIGILAB FTS 3000 FT-IR spectrophotometer (Digilab Inc., Boston, MA, USA) under the transmission mode. The ground samples were dispersed into $\mathrm{KBr}$ pellets at mass ratio of 1:60. At spectral resolution of $2 \mathrm{~cm}^{-1}$, the data were collected in the wavenumber range of $4000-400 \mathrm{~cm}^{-1}$ after 64 scans. SEM studies were carried out on a JSM-5600 LV scanning electron microscope (Japan Electron Optics Laboratory Co. Ltd., Tokyo, Japan) after coating the sample with platinum film using an acceleration voltage of $20 \mathrm{kV}$. Thermogravimetric analysis (TGA) was carried out in a Perkin-Elmer TGA-7 thermogravimetric analyzer PE TG/DTA 6300 
instrument (Perkin-Elmer Inc., Boston, MA, USA) over a temperature range of $20-800{ }^{\circ} \mathrm{C}$, at a nitrogen flow rate of $50 \mathrm{~mL} \mathrm{~min}{ }^{-1}$ under a heating rate of $10{ }^{\circ} \mathrm{C} \mathrm{min}^{-1}$. The particle size distribution of the composite was measured by dynamic light scattering (DLS) on a NICOMP 380N3000 nanoparticle size analyzer (PSS, Santa Barbara, CA, USA). The laser wavelength was $514.5 \mathrm{~nm}$ and the solvent was water.

\subsection{Adsorption of $\mathrm{Hg}(\mathrm{II}) \mathrm{Ions}$}

A total of $50 \mathrm{~mL}$ of $\mathrm{Hg}$ (II) solution with an initial concentration of $15 \mathrm{mg} \cdot \mathrm{L}^{-1}$ was added into a conical flask. The $\mathrm{pH}$ of the solution was adjusted to 5.5 with hydrochloric acid of $\mathrm{pH}=2$ and $\mathrm{NaOH}$ solution of $\mathrm{pH}=12$. Then $0.01 \mathrm{~g}$ of graft copolymer was put into the solution for $\mathrm{Hg}$ (II) ion adsorption experiment. The adsorption equilibrium was achieved by stirring at $120 \mathrm{rpm}$ for $2 \mathrm{~h}$ at $45^{\circ} \mathrm{C}$. After centrifugation, the concentration of $\mathrm{Hg}(\mathrm{II})$ in the supernatant was determined by atomic absorption spectrophotometer. The adsorption capacity $\left(\mathrm{mg} \cdot \mathrm{g}^{-1}\right.$ ) of the graft copolymer for $\mathrm{Hg}$ (II) ion was calculated by Formula (1):

$$
Q_{t}=\frac{\left(C_{i}-C_{t}\right)}{W} V
$$

where $Q_{t}$ is the adsorption capacity of metal ions at time t. $C_{i}$ and $C_{t}$ are the initial and final concentrations of $\mathrm{Hg}(\mathrm{II})$ ion $\left(\mathrm{mg} \cdot \mathrm{L}^{-1}\right)$, respectively. $V$ is the volume of $\mathrm{Hg}(\mathrm{II})$ ion solution and $W$ is the mass of graft copolymer.

\subsection{Regeneration of the PAA-AM/St Composite}

The PAA-AM/St composite that reached the saturated adsorption of $\mathrm{Hg}(\mathrm{II})$ ions was put into a $250 \mathrm{~mL}$ flask, in which $65 \mathrm{~mL}$ of $1 \mathrm{~mol} \cdot \mathrm{L}^{-1} \mathrm{NaOH}$ solution was added. Heating the mixture to $55^{\circ} \mathrm{C}$ for $1.5 \mathrm{~h}$ under refluxing, the desorption experiment was carried out. After the desorption, the mixture was centrifuged and the supernatant was discarded. The composite was precipitated again by adding the mixture of methanol and water (volume ratio 5:1). After being washed several times with a mixture of distilled water and methanol (1:1 by volume), the composite was then dried in a vacuum oven.

\section{Results and Discussion}

The starch-g-poly (acrylic acid acrylamide) graft copolymer was prepared by solution polymerization through free radical mechanism [24,25]. The graft copolymerization was carried out according to the stoichiometric equation (shown in Figure 1).

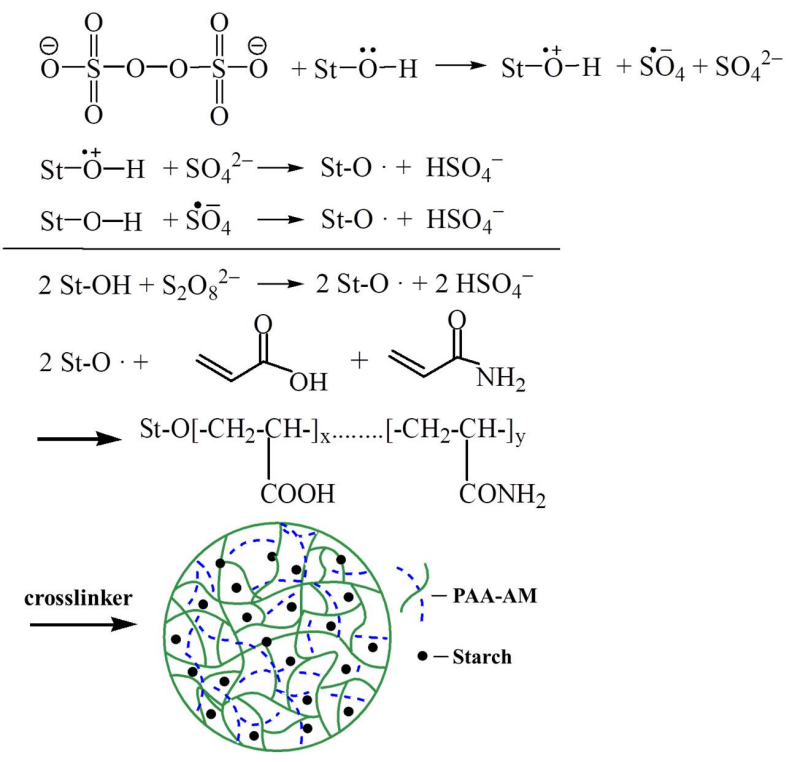

Figure 1. Schematic illustration of polymerization. 


\subsection{Measurement of Molecular Weight}

The molecular weight of the PAA-AM/St composite was determined by SEC. The composite was run in the chromatographic column and the molecular weight distribution curve was constructed by fraction elution and calibration plot. $M_{n}, M_{p}, M_{w}, M_{z}$ and $M_{z+1}$ values were located in Figure 2. The relative standard deviation (RSD) of the measurement results in Figure 2 were listed in Table 1. All the RSD values are less than 5\%, which indicates that the SEC method performed is accurate and reliable [26]. PDI is defined as the ratio of $M_{w}$ to $M_{n}$ [27]. Generally speaking, the larger the PDI value is, the wider the molecular weight distribution is, the smaller the PDI value is, the narrower the molecular weight distribution is [28]. The PDI values of starch and PAA-AM/St composite calculated from Table 1 are 1.06 and 1.07, respectively. Both of them are less than 1.10, which means that the molecular weight distribution of the PAA-AM/St composite is relatively narrow, and the chain length of the polymer is relatively uniform [29].

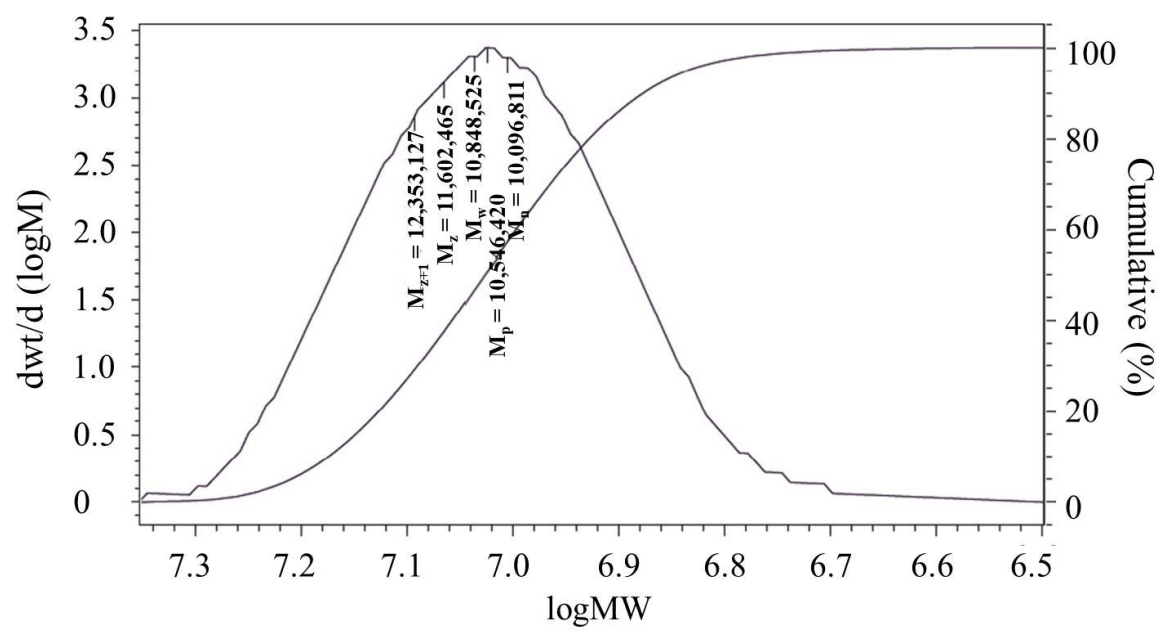

Figure 2. The molecular weight and the molecular weight distribution of PAA-AM/St.

Table 1. Different average molecular weights of starch and PAA-AM/St.

\begin{tabular}{ccccccccccc}
\hline Sample & $\mathbf{M}_{\mathbf{n}}$ & $\mathbf{R S D}$ & $\mathbf{M}_{\mathbf{p}}$ & $\mathbf{R S D}$ & $\mathbf{M}_{\mathbf{w}}$ & $\mathbf{R S D}$ & $\mathbf{M}_{\mathbf{z}}$ & $\mathbf{R S D}$ & $\mathbf{M}_{\mathbf{z}+\mathbf{1}}$ & $\mathbf{R S D}$ \\
\hline Starch & 876,032 & $4.7 \%$ & 906,360 & $4.0 \%$ & 933,126 & $2.3 \%$ & 936,921 & $0.9 \%$ & 967,686 & $0.7 \%$ \\
\hline $\begin{array}{c}\text { PAA- } \\
\text { AM/St }\end{array}$ & $10,096,811$ & $4.5 \%$ & $10,546,420$ & $3.0 \%$ & $10,848,525$ & $2.1 \%$ & $11,602,465$ & $1.0 \%$ & $12,353,127$ & $0.9 \%$ \\
\hline
\end{tabular}

\subsection{FT-IR Spectra}

The infrared spectra of starch and graft copolymer are shown in Figure 3. The peak at $1642 \mathrm{~cm}^{-1}$ was the stretching vibration band of carbonyl group in AM and at $1728 \mathrm{~cm}^{-1}$ was caused by stretching vibration of $\mathrm{C}=\mathrm{O}$ in $\mathrm{AA}$ (Figure $3 \mathrm{~b}$ ). There were no such peaks in starch (Figure 3a). The broad and strong absorption band near $3450 \mathrm{~cm}^{-1}$ represents the stretching vibration of $-\mathrm{OH}$ group in AA and -NH group in AM [30]. The $1400 \mathrm{~cm}^{-1}$ is related to the stretching vibration of C-N bond in graft copolymer [31]. Since the homopolymer was completely removed, the peaks at $1642 \mathrm{~cm}^{-1}$ and $1728 \mathrm{~cm}^{-1}$ indicate that the poly (acrylic acid-acrylamide) chain was successfully grafted into the starch structure. 


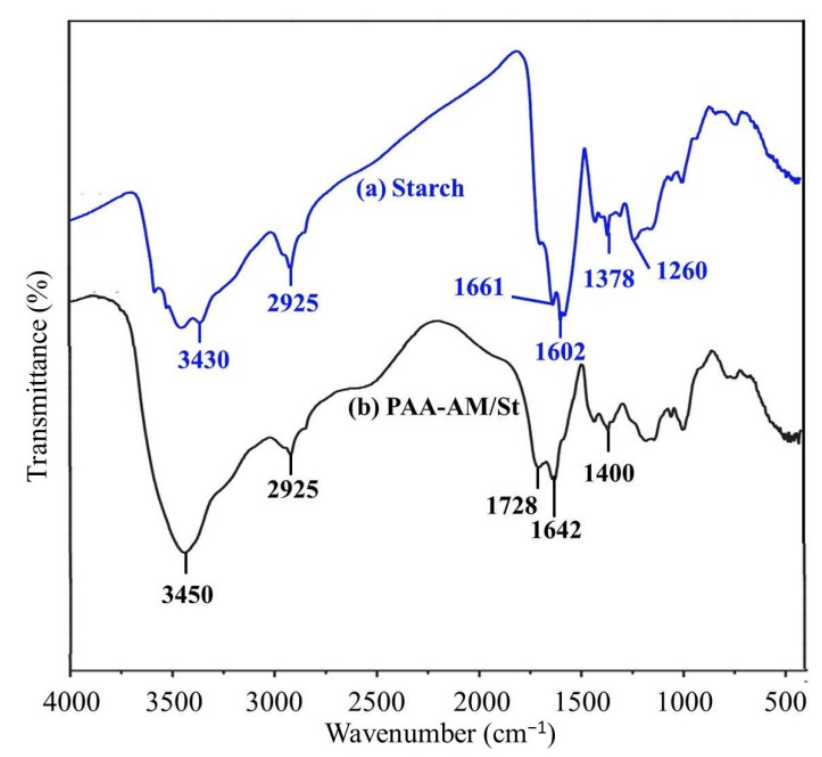

Figure 3. FT-IR spectra of (a) starch and (b) PAA-AM/St composite.

\subsection{Thermal Stability}

The thermogravimetric curve of starch is shown in Figure 4. It can be seen that the starch had undergone three stages of decomposition, the main mass loss occurred in the temperature range of $264-337^{\circ} \mathrm{C}$ and the weight loss rate was up to $68 \%$ at $316^{\circ} \mathrm{C}$ [26]. The thermogravimetric curve of the PAA-AM is shown in Figure 5. It can be seen that the PAA-AM also underwent three stages of decomposition, the main weight loss occurred between 300 and $368^{\circ} \mathrm{C}$. The maximum weight loss happened at $347^{\circ} \mathrm{C}$. There were two characteristic peaks between 263 and $331^{\circ} \mathrm{C}$ and 331 and $400{ }^{\circ} \mathrm{C}$ of PAA-AM/St, and the significant weight loss occurred at $316^{\circ} \mathrm{C}$ and $342{ }^{\circ} \mathrm{C}$, respectively (as shown in Figure 6). The weight loss between 263 and $331^{\circ} \mathrm{C}$ corresponded to the collapse of the main structure of starch, while the weight loss between 331 and $400{ }^{\circ} \mathrm{C}$ was due to the collapse of the chain structure of PAA-AM copolymers $[27,28]$. The results show that the poly (acrylicacrylamide) chain was successfully grafted onto the starch structure. The total weight loss of starch and PAA-AM copolymer was $85 \%$ and $67 \%$ respectively at $400{ }^{\circ} \mathrm{C}$, while that of PAA-AM/St composite was 73\%. Therefore, it can be concluded that the grafting poly (acrylic acid-acrylamide) with starch is a promising way to obtain thermally stable composite than pure starch.

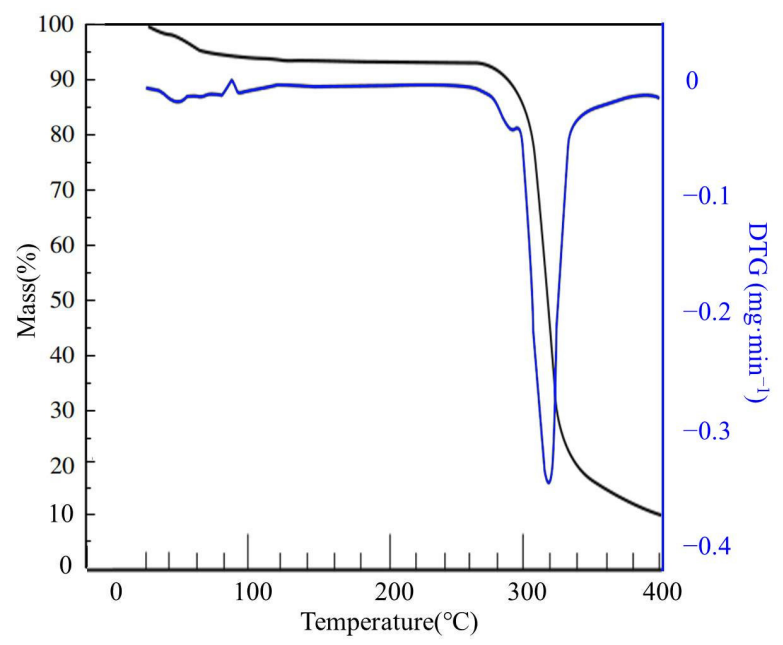

Figure 4. The TG and DTG curves of starch. 


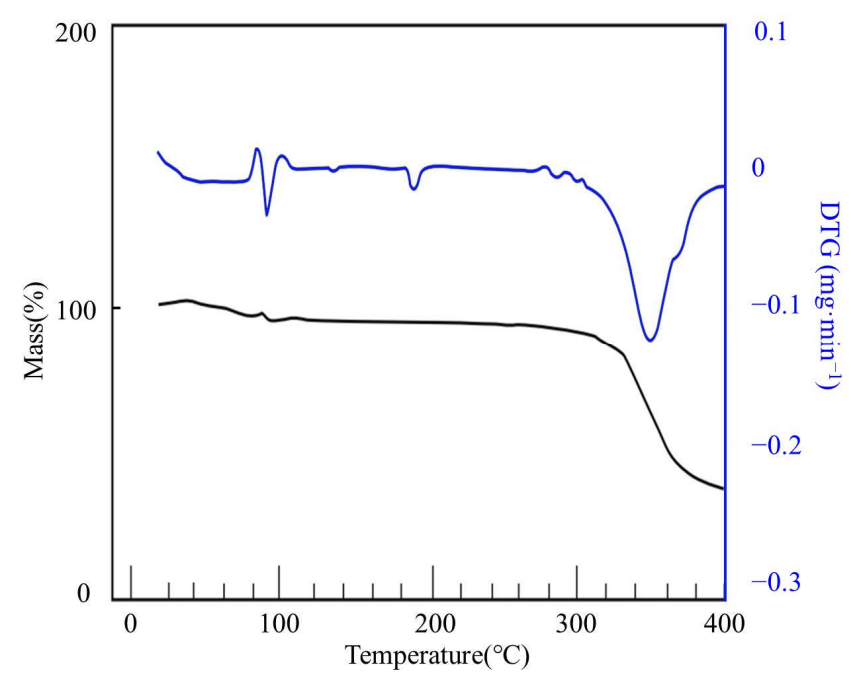

Figure 5. The TG and DTG curves of PAA-AM.

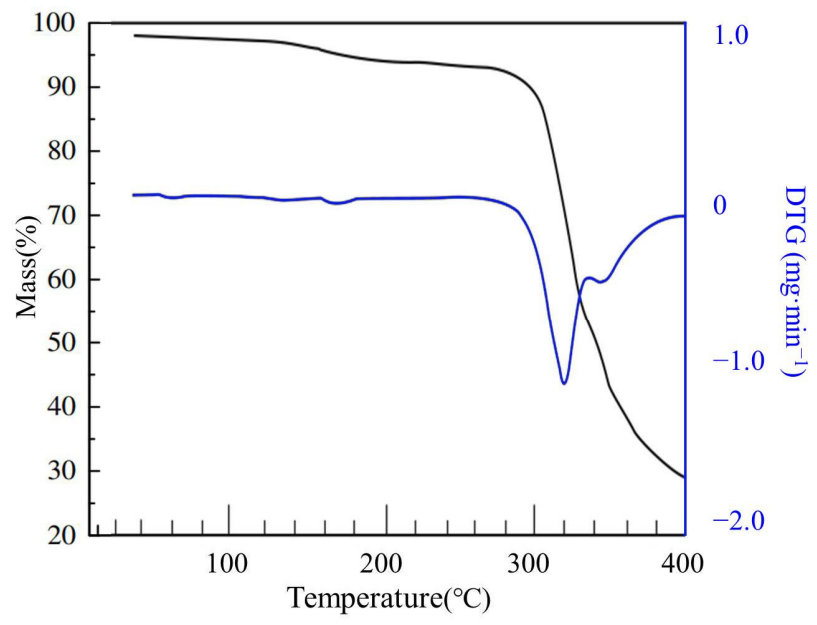

Figure 6. The TG and DTG curves of PAA-AM/St.

\subsection{Morphology Analysis}

The surface morphology of the starch, PAA-AM and PAA-AM/St were observed using scanning electron microscopy (SEM). It can be seen from Figure 7a that the electron micrographs of pure starch samples clearly exhibited irregularly shaped granular structure. Figure $7 \mathrm{~b}$ shows that integrating starch particles into PAA-AM copolymer can form composites with large specific surface area and uniform morphology. Evidently, incorporating starch granules onto PAA-AM matrix generated a flower shaped structure with starch evenly packaged by PAA-AM. With the formation of a large number of gaps and ravines on the surface, the specific surface area of the composite increased sharply, which makes it easier to carry more active adsorption sites. Therefore, $\mathrm{Hg}$ (II) ions can be easily adsorbed. The morphology of PAA-AM/St (Figure 7b) can be divided into three parts. The bright bulges are presumed to be the furrows in the composite, the gray area are probably the gullies between the furrows, and the dark regions are speculated to be cavities created during graft copolymerization [32]. Combining all these three parts, PAA-AM/St was composed of fine particles, possessing not only a uniform and stable structure but also very large surface area. Comparing with the morphology of PAA-AM shown in Figure 7c, it is easy to find out that the introduction of starch makes the surface of the PAA-AM/St composite much coarser than that of PAA-AM. Not any significant fracture between starch and PAA-AM matrix is observed in the composite, which proved that starch and PAA-AM chains were successfully integrated. 


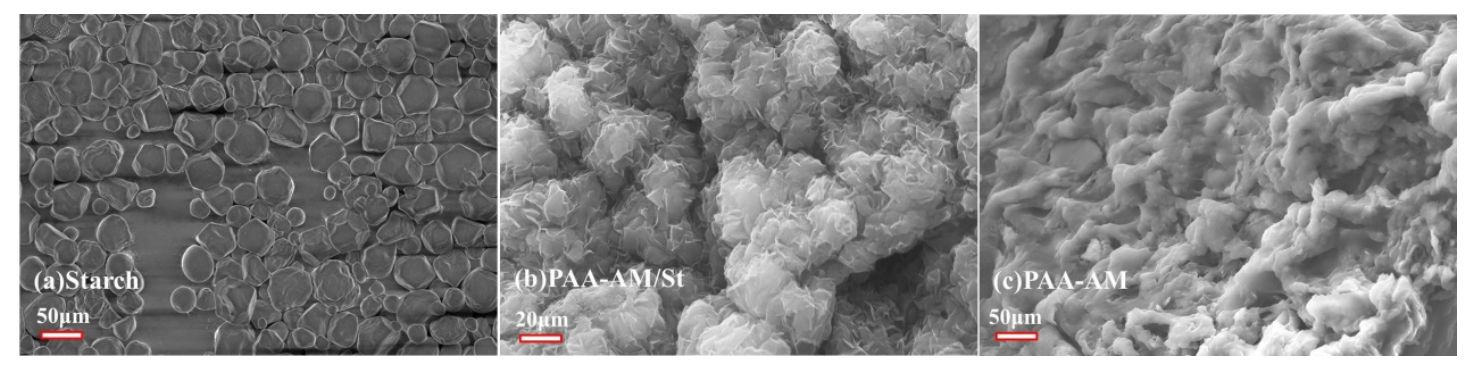

Figure 7. SEM images of (a) starch, (b) PAA-AM/St and (c) PAA-AM.

\subsection{DLS Study}

The particle size distribution of the composite was analyzed by dynamic light scattering test. The results are shown in Figure 8, from which it can be found that the particle diameter distribution of the composite was not significantly different under different centrifugal velocities. It can be seen from the figure that the most probable particle size of PAA-AM/St was $205 \mathrm{~nm}$ under $3500 \mathrm{rpm}$ centrifugation, and the particle size distributed in the range of 50-520 nm. The maximum particle size of PAA-AM/St under 6000-8000 rpm centrifugation was $268 \mathrm{~nm}$, and the particle size distribution was in the range of 50-600 nm. This means that even at high centrifugal strength, PAA-AM/St particles of different sizes will not be separated [33].

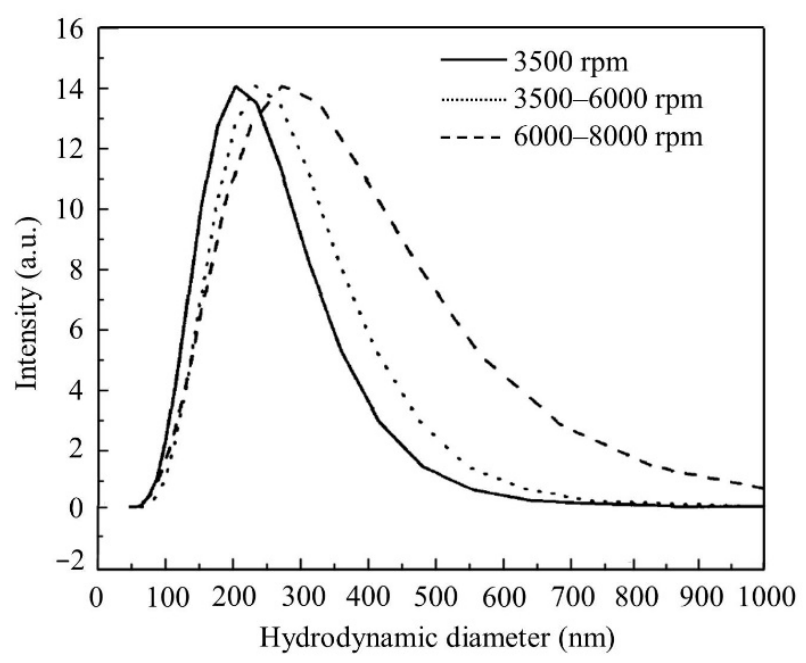

Figure 8. Particle size and distribution of the PAA-AM/St composite.

\subsection{Optimization of $\mathrm{Hg}(\mathrm{II})$ Ions Adsorption Conditions}

3.6.1. Effect of Contact Time on the Adsorption of $\mathrm{Hg}$ (II) Ions by the Graft Polymer

Firstly, the effect of contact time on the adsorption of $\mathrm{Hg}$ (II) ions was investigated. Figure 9 showed the relationship between the contact time and the adsorption capacity of PAA-AM/St composite. Within a certain time range (0-600 $\mathrm{min})$, the adsorption of $\mathrm{Hg}$ (II) ions by graft copolymers increased sharply at first $(0-50 \mathrm{~min})$ and then tended to equilibrium. Maximum adsorption occurred at $120 \mathrm{~min}$. This is because the surface area of the graft copolymer is very large, carrying a large number of adsorption active sites [34]. As the adsorption process proceeds, the vacant active sites are gradually occupied. When the adsorption active sites are gradually saturated with the $\mathrm{Hg}$ (II) ions, the adsorption process reaches equilibrium [35]. 


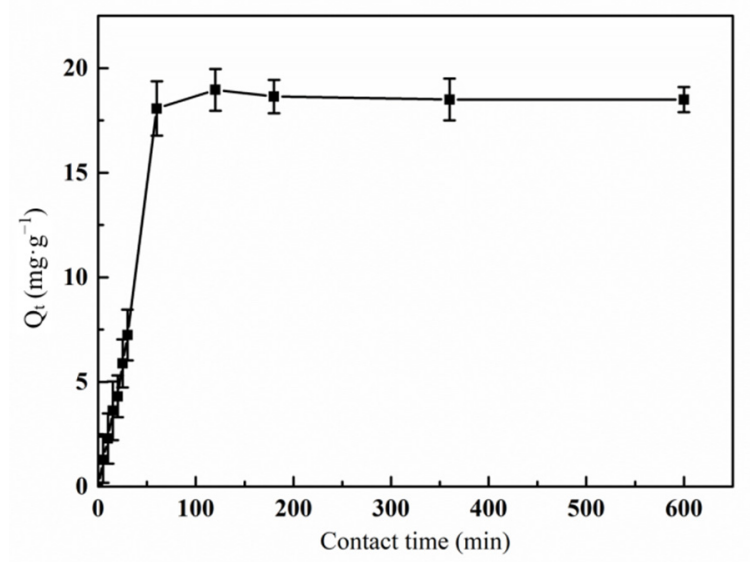

Figure 9. Effect of contact time on the adsorption of $\mathrm{Hg}$ (II) ions by graft polymer ( $\mathrm{pH}$ value 5.5; initial concentration of $\mathrm{Hg}(\mathrm{II})$ ion $15 \mathrm{mg} \cdot \mathrm{L}^{-1}$; treatment temperature $45^{\circ} \mathrm{C}$ ).

\subsubsection{Effect of $\mathrm{pH}$ Value on the Adsorption of $\mathrm{Hg}$ (II) Ions by the Graft Polymer}

The change of adsorption capacity of graft copolymer for $\mathrm{Hg}$ (II) ion with $\mathrm{pH}$ value was shown in Figure 10. It can be seen from the figure that the $\mathrm{pH}$ of the solution had a significant effect on the adsorption of $\mathrm{Hg}$ (II) ions by the graft copolymer. In the low $\mathrm{pH}$ environment, $\mathrm{H}^{+}$in the solution and the lone pair electrons on the $\mathrm{N}$ atom of the $-\mathrm{NH}_{2}$ group in $\mathrm{AM}$ formed hydrogen bonds, which makes the $-\mathrm{NH}_{2}$ group unable to combine with positively charged $\mathrm{Hg}$ (II) ions. Meanwhile, with the existence of massive $\mathrm{H}^{+}$, the carboxyl group from AA almost always kept the protonated form - $\mathrm{COOH}$, which does not have the ability to combine with mercury (II) ions, either [36]. The adsorption capacity of the graft copolymer for $\mathrm{Hg}$ (II) increased with the raise of $\mathrm{pH}$, and decreased after reaching a certain $\mathrm{pH}$ value (5.5). When the $\mathrm{pH}$ value was 5.5 , the adsorption capacity reached the top. This is because while the $\mathrm{pH}$ value kept on increasing, $-\mathrm{COOH}$ dissociated into $-\mathrm{COO}^{-}$, which can combine with positively charged $\mathrm{Hg}$ (II) ions [37]. As the effective adsorption sites are gradually occupied, the adsorption process will slow down and gradually tend to equilibrium.

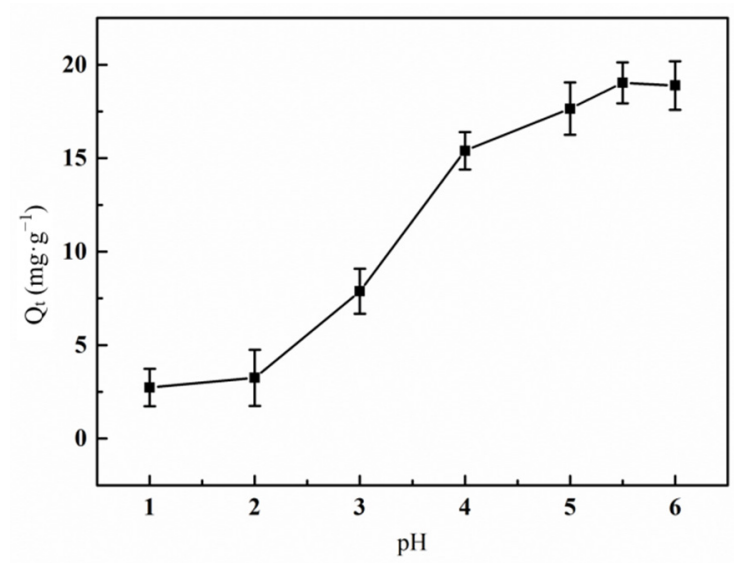

Figure 10. Effect of $\mathrm{pH}$ value on the adsorption of $\mathrm{Hg}$ (II) ions by graft polymer (contact time $120 \mathrm{~min}$; initial concentration of $\mathrm{Hg}(\mathrm{II})$ ion $15 \mathrm{mg} \cdot \mathrm{L}^{-1}$; treatment temperature $45^{\circ} \mathrm{C}$ ).

3.6.3. Effect of Initial $\mathrm{Hg}$ (II) Ions Concentration on the Adsorption Property by Graft Polymer

The effect of the adsorption capacity of $\mathrm{Hg}$ (II) ions on the graft copolymer with the initial $\mathrm{Hg}$ (II) ions concentration is shown in Figure 11. Obviously, when the initial concentration of $\mathrm{Hg}(\mathrm{II})$ ion increased from 2.5 to $15.0 \mathrm{mg} \cdot \mathrm{L}^{-1}$, the binding sites on the graft copolymer were sufficient, and the low concentration $\mathrm{Hg}$ (II) ion can be fully adsorbed 
on the active sites in an orderly manner [38]. With the increase of initial concentration of $\mathrm{Hg}$ (II), there were too many $\mathrm{Hg}$ (II) ions in the unit volume solution. Parts of $\mathrm{Hg}$ (II) ions quickly occupy the active sites on the surface, forming a positive layer on the surface of the graft copolymer, which blocks the further adsorption of $\mathrm{Hg}$ (II) ions. Therefore, the adsorption capacity decreased gradually.

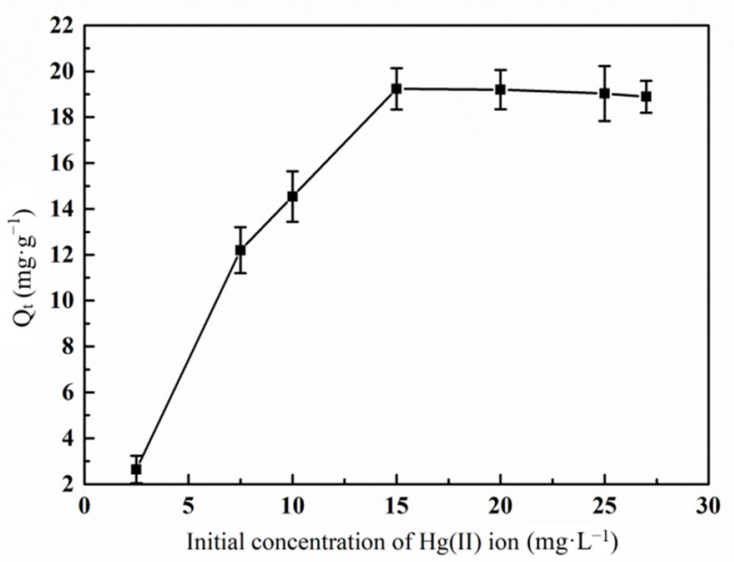

Figure 11. Effect of initial concentration of $\mathrm{Hg}$ (II) ion on the adsorption of $\mathrm{Hg}$ (II) ions by graft polymer (contact time $120 \mathrm{~min}$; $\mathrm{pH}$ value 5.5; treatment temperature $45^{\circ} \mathrm{C}$ ).

The effect of time on $\mathrm{Hg}$ (II) adsorption capacity at different initial concentrations was investigated. The data is then fitted by the pseudo first order model (Formula (2)) and pseudo second order model (Formula (3)) to conduct adsorption kinetics study. Plot $\log \left(q_{e}\right.$ $-q_{t}$ ) versus $t$ to perform pseudo first order model fitting. Plot $t / q_{t}$ versus $t$ to perform pseudo second order model fitting [24]. The relevant parameters are listed in Table 2. It can be seen from the $\mathrm{R}^{2}$ value that the adsorption kinetics of $\mathrm{Hg}$ (II) on the composite fits well with the pseudo second order model.

$$
\begin{gathered}
\log \left(q_{e}-q_{t}\right)=\log q_{e}-\frac{k_{1}}{2.303} t \\
\frac{t}{q_{t}}=\frac{1}{k_{2} q_{e}^{2}}+\frac{t}{q_{e}}
\end{gathered}
$$

Table 2. The relevant parameters for pseudo first order adsorption and pseudo second order adsorp-

\begin{tabular}{|c|c|c|c|c|}
\hline \multirow{2}{*}{$\begin{array}{l}\text { Initial Concentration } \\
\text { of } \mathrm{Hg}(\mathrm{II})\left(\mathrm{mg} \cdot \mathrm{L}^{-1}\right)\end{array}$} & \multicolumn{2}{|c|}{ Pseudo First Order Model } & \multicolumn{2}{|c|}{ Pseudo Second Order Model } \\
\hline & $\mathrm{k}_{1}\left(\min ^{-1}\right)$ & $\mathbf{R}^{2}$ & $\mathrm{k}_{2}\left(\mathrm{~g} \cdot \mathrm{mg}^{-1} \cdot \min ^{-1}\right)$ & $\mathbf{R}^{2}$ \\
\hline 3.0 & $2.3 \times 10^{-2}$ & 0.325 & $3.3 \times 10^{-3}$ & 0.999 \\
\hline 7.0 & $3.1 \times 10^{-3}$ & 0.103 & $8.9 \times 10^{-4}$ & 0.999 \\
\hline 9.0 & $3.3 \times 10^{-3}$ & 0.386 & $8.1 \times 10^{-4}$ & 0.999 \\
\hline 15.0 & $4.1 \times 10^{-3}$ & 0.468 & $6.4 \times 10^{-4}$ & 0.999 \\
\hline 26.5 & $4.3 \times 10^{-3}$ & 0.369 & $5.2 \times 10^{-4}$ & 0.999 \\
\hline 30 & $4.2 \times 10^{-3}$ & 0.412 & $4.9 \times 10^{-4}$ & 0.999 \\
\hline
\end{tabular}
tion.

In the above formula, $k_{1}$ and $k_{2}$ are the rate constants of the pseudo first-order model and the pseudo second-order model, respectively; $q_{e}$ and $q_{t}$ are the adsorption capacities at equilibrium and at time $t$, respectively.

\subsubsection{Effect of Temperature on the Adsorption of $\mathrm{Hg}$ (II) Ions by the Graft Polymer}

The influence of temperature on the adsorption capacity of metal ions mainly depends on the chemical structure of the adsorbent surface and the physicochemical state of the 
solution. When the temperature rises from 25 to $45^{\circ} \mathrm{C}$, the adsorbent swells well in the $\mathrm{Hg}$ (II) solution thanks to the thermal energy, exposing more active adsorption sites on the adsorbent surface. Therefore, in this temperature range, the increase of temperature is helpful to enhance the adsorption. However, the spontaneous adsorption reaction is an exothermic process. Generally speaking, in order to obtain a better adsorption effect, the treatment temperature should not be too high [39]. Figure 12 further confirms this view. When the solution temperature exceeds $45^{\circ} \mathrm{C}$, the increase of temperature cause the decrease of adsorption capacity [40].

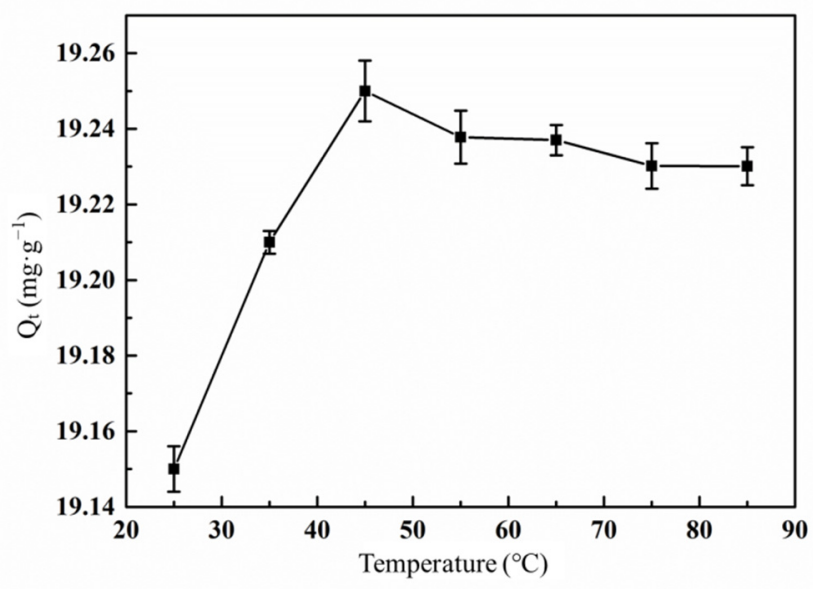

Figure 12. Effect of treatment temperature on the adsorption of $\mathrm{Hg}$ (II) ions by the graft polymer (contact time $120 \mathrm{~min}$; $\mathrm{pH}$ value 5.5; initial concentration of $\mathrm{Hg}(\mathrm{II})$ ion $15 \mathrm{mg} \cdot \mathrm{L}^{-1}$ ).

\subsection{Recyclability Study}

The results of the adsorption-desorption experiments are shown in Figure 13. It can be seen that the adsorption capacity of the graft copolymer on the $\mathrm{Hg}(\mathrm{II})$ ion decreased to $78 \%$ of the original adsorption capacity after the treatment of the $1 \mathrm{~mol} \cdot \mathrm{L}^{-1} \mathrm{NaOH}$ solution. After the third cycle, the adsorption capacity decreased to $23 \%$ of the original. The damage of the $1 \mathrm{~mol} \cdot \mathrm{L}^{-1} \mathrm{NaOH}$ solution caused to the PAA-AM/St composite is catastrophic, but the composite can still reach $78 \%$ of the original adsorption capacity when it is recycled. This indicates that the PAA-AM/St composite prepared in this study can put up a good adsorption performance for $\mathrm{Hg}$ (II) ion under a severe situation.

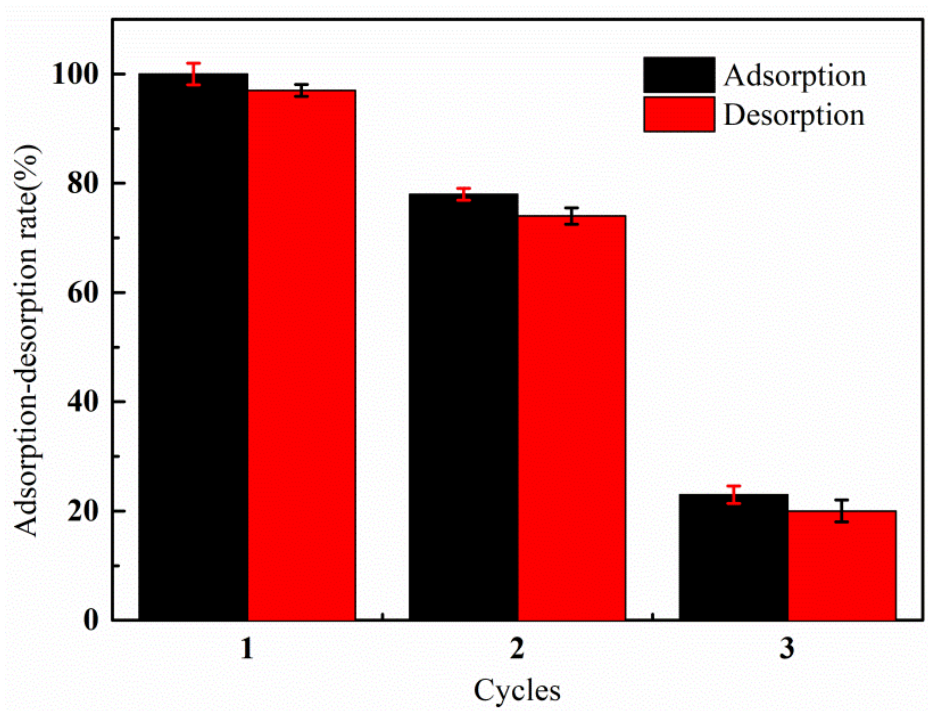

Figure 13. Adsorption-desorption rate in $1 \mathrm{~mol} \cdot \mathrm{L}^{-1} \mathrm{NaOH}$ solution under different cycles. 


\subsection{Comparison Study}

The adsorption capacities of various composite materials for the $\mathrm{Hg}$ (II) ion at different initial concentrations were summarized in Table 3. According to the data in the comparison table, when the initial concentration of $\mathrm{Hg}$ (II) ion varied between 100 and $4000 \mathrm{mg} \cdot \mathrm{L}^{-1}$, all kinds of composites showed good adsorption capacity for $\mathrm{Hg}(\mathrm{II})$ ion $\left(94.33-798.92 \mathrm{mg} \cdot \mathrm{g}^{-1}\right.$ ). When the initial concentration of $\mathrm{Hg}$ (II) ion was less than $100 \mathrm{mg} \cdot \mathrm{L}^{-1}$, the adsorption capacities of the composites for $\mathrm{Hg}(\mathrm{II})$ ion ranged from 5.64 to $21.52 \mathrm{mg} \cdot \mathrm{g}^{-1}$. Considering that the concentration of $\mathrm{Hg}$ (II) ion is generally not high in practical pollution, $15 \mathrm{mg} \cdot \mathrm{L}^{-1}$ was chosen as the initial concentration of $\mathrm{Hg}$ (II) ion in this study, and it was found that the PAA-AM/St composite synthesized in this study achieved a satisfactory adsorption effect on the $\mathrm{Hg}(\mathrm{II})$ ion.

Table 3. Adsorption capacity of various composite materials for $\mathrm{Hg}(\mathrm{II})$ ion at different initial concentrations.

\begin{tabular}{|c|c|c|c|}
\hline Composites Used as Adsorbent & Initial Concentration of $\mathrm{Hg}(\mathrm{II})$ ion $\left(\mathrm{mg} \cdot \mathrm{L}^{-1}\right)$ & $Q_{t}\left(m g \cdot g^{-1}\right)$ & Reference \\
\hline PAN-AA/AMP & 200 & 221.23 & {$[1]$} \\
\hline PAN-AA & 200 & 202.43 & [1] \\
\hline St-PEG-PAA & 300 & 158.21 & [7] \\
\hline AgNPs-St-PEG-PAA & 300 & 182.53 & [7] \\
\hline $\mathrm{P} 3 \mathrm{HT}-\mathrm{CNT} / \mathrm{Ti}$ & 200 & 164 & {$[20]$} \\
\hline PAA-MWCNTs & 18 & 5.64 & [22] \\
\hline PNMA-AA/St & 27.5 & 7.9 & {$[24]$} \\
\hline PAN-PRGO & 150 & 164.79 & [34] \\
\hline P(AA-co-MA-co-DMTU) & 400 & 198.23 & {$[37]$} \\
\hline PAA-DMDAAC/St & 4000 & 191.97 & [38] \\
\hline CTS-g-PAA & 3669 & 798.92 & [40] \\
\hline CTS-g-PAA/50\%APT & 3669 & 503.21 & [41] \\
\hline CJ-g-PAA & 500 & 135 & [42] \\
\hline Cys-C@Fe $\mathrm{F}_{3} \mathrm{O}_{4}$ & 100 & 94.33 & [19] \\
\hline MBI-OHTC & 25 & 11.63 & [27] \\
\hline MBI-OHTC & 50 & 21.52 & [27] \\
\hline $\mathrm{PAA}-\mathrm{AM} / \mathrm{St}$ & 15 & 19.23 & This work \\
\hline
\end{tabular}

Abbreviations in Table 3: AN—acrylonitrile; AMP—acrylonitrile; PEG-polyethylene glycol; AgNPs—silver nanoparticles; P3HT-3Hexylthiophene; CNT—carbon nanotube; MWCNTs—multiwall carbon nanotubes; NMA-N-methylacrylamide; PRGO-partial reduction graphene oxide; MA—-partial reduction graphene oxide; DMTU—dimethylthiourea; DMDAAC-dimethyl diallyl ammonium chloride; CTS—chitosan; APT—attapulgite; CJ—cassia javanica seed gum; Cys—cysteine; C—carbon; MBI-2-Mercaptobenzimidazole; OHTC— organophilic calcined hydrotalcite.

\section{Conclusions}

The starch-g-poly (acrylic acid-acrylamide) composite was synthesized from starch, acrylic acid and acrylamide. SEC characterization indicated that the graft copolymer exhibited narrow molecular weight distribution. The FT-IR spectra showed that starch was successfully integrated with the macromolecular polymer matrix and played a key role for improving the performance of the composites. The TG tests revealed that the thermal stability of PAA-AM/St was superior to that of PAA-AM and starch within $300^{\circ} \mathrm{C}$. The SEM images declared that the PAA-AM/St composite embodied rough but uniform morphological feature. The DLS analysis explained that the composite had a narrow particle size distribution and will not be separated even at high speed centrifugation conditions.

The graft copolymer was also used to remove heavy metal ions from aqueous solution, and its adsorption performance for mercury (II) in aqueous solution was studied. The influence of contact time, $\mathrm{pH}$ value, initial $\mathrm{Hg}$ (II) ions concentration and treatment temperature on the adsorption capacity were researched. The results indicated that the composite achieved the maximum adsorption of $19.23 \mathrm{mg} \cdot \mathrm{g}^{-1}$ to $\mathrm{Hg}(\mathrm{II})$ ions in aqueous solution whose initial concentration of $\mathrm{Hg}$ (II) ion was $15 \mathrm{mg} \cdot \mathrm{L}^{-1}$. Compared with the published literature, this adsorption capacity is a good result in the reported studies on the adsorption of $\mathrm{Hg}$ (II) ions by composite materials. The PAA-AM/St composite synthesized 
in this research shows excellent adsorption for $\mathrm{Hg}$ (II) ions in dilute solution, which is of great practical significance in the field of treating wastewater actually polluted by $\mathrm{Hg}$ (II) ions. The graft copolymer can be used as $\mathrm{Hg}$ (II) ion adsorbent to effectively remove toxic $\mathrm{Hg}$ (II) ions in wastewater. However, considering the fact that the concentration of $\mathrm{Hg}$ (II) ions in most wastewater is not high in practical application, more attempt should be made to improve the treatment efficiency of composite materials for wastewater with low concentration of heavy metal ions in further research.

Author Contributions: Conceptualization, W.Z. and A.Y.; Methodology, W.Z. and Z.Y.; Software, A.Y. and L.Z.; Validation, Y.L., Z.Y. and A.Y.; Formal Analysis, Z.Y. and L.Z.; Investigation, W.Z. and Y.L.; Resources, Z.Y.; Data Curation, W.Z. and Z.Y.; Writing-Original Draft Preparation, W.Z.; WritingReview \& Editing, W.Z.; Visualization, A.Y. and L.Z.; Supervision, W.Z.; Project Administration, W.Z.; Funding Acquisition, W.Z. All authors contributed substantially to the work reported. All authors have read and agreed to the published version of the manuscript.

Funding: This work was financially supported by the Doctoral Initiation Grant Program of Xinjiang University of Engineering (2019BQJ022207).

Institutional Review Board Statement: Not applicable.

Informed Consent Statement: Not applicable.

Data Availability Statement: The data presented in this study are available on request from the corresponding author.

Conflicts of Interest: The authors declare no conflict of interest.

\section{References}

1. El-Zahhar, A.A.; Idris, A.M. Mercury(II) decontamination using a newly synthesized poly(acrylonitrile-acrylic acid)/ammonium molybdophosphate composite exchanger. Toxin Rev. 2020, 1, 1-13. [CrossRef]

2. Sun, J. Removal of Mercury ( $\mathrm{Hg}(\mathrm{II}))$ from Seaweed Extracts by Electrodialysis and Process Optimization Using Response Surface Methodology. J. Ocean Univ. China 2020, 19, 135-142. [CrossRef]

3. Abdel-Aal, S.E.; Gad, Y.H.; Dessouki, A.M. The use of wood pulp and radiation-modified starch in wastewater treatment. J. Appl. Polym. Sci. 2010, 99, 2460-2469. [CrossRef]

4. Igura, M.; Okazaki, M. Selective sorption of heavy metal on phosphorylated sago starch-extraction residue. J. Appl. Polym. Sci. 2012, 124, 549-559. [CrossRef]

5. Feng, K.; Wen, G. Absorbed $\mathrm{Pb}^{2+}$ and $\mathrm{Cd}^{2+}$ Ions in Water by Cross-Linked Starch Xanthate. Int. J. Ploym. Sci. 2017, 58, 275-276. [CrossRef]

6. Shahzamani, M.; Taheri, S.; Roghanizad, A.; Naseri, N.; Dinari, M. Preparation and characterization of hydrogel nanocomposite based on nanocellulose and acrylic acid in the presence of urea. Int. J. Biol. Macromol. 2020, 147, 187-193. [CrossRef]

7. Saberi, A.; Sadeghi, M.; Alipour, E. Design of AgNPs -Base Starch/PEG-Poly (Acrylic Acid) Hydrogel for Removal of Mercury (II). J. Polym. Environ. 2020, 28, 303-315. [CrossRef]

8. Hadavifar, M.; Bahramifar, N.; Younesi, H.; Qin, L. Adsorption of mercury ions from synthetic and real wastewater aqueous solution by functionalized multi-walled carbon nanotube with both amino and thiolated groups. Chem. Eng. J. 2014, 237, 217-228. [CrossRef]

9. Peng, C.; He, M.; Chen, B.; Huang, L.; Hu, B. Magnetic sulfur-doped porous carbon for preconcentration of trace mercury in environmental water prior to ICP-MS detection. Analyst 2017, 142, 4570-4583. [CrossRef] [PubMed]

10. Sreedhar, M.K.; Anirudhan, T.S. Preparation of an adsorbent by graft polymerization of acrylamide onto coconut husk for mercury(II) removal from aqueous solution and chloralkali industry wastewater. J. Appl. Polym. Sci. 2000, 75, 1261-1269. [CrossRef]

11. Fatiha, B.; Hayet, B.; Zohra, F.; Radjaa, B.; Hfz, B. Journal of Drug Delivery and Therapeutics Toxicity of mercury on the brain: Ability of extract of Pistacia atlantica regulated effect. J. Drug Deliv. Ther. 2020, 10, 17-25. [CrossRef]

12. Teixeira, G.; Raimundo, J.; Goulart, J.; Costa, V.; Martins, I. Hg and Se composition in demersal deep-sea fish from the North-East Atlantic. Environ. Sci. Pollut. Res. 2020, 27, 24-36. [CrossRef]

13. Amani, V.; Sharafie, D.; Hamedani, N.F.; Naseh, M. Zinc(II) and mercury(II) iodide complexes containing 2-pyridinealdoxime compound: Synthesis, characterization, crystal structure determination and DFT study. J. Iran. Chem. Soc. 2020, 17, 441-451. [CrossRef]

14. Tripathi, N.K. Equilibrium studies of Mercury (II), Lead (II) and Cadmium (II) ions involving Aspartic acid and Thymine. Int. J. Res. Pharm. Chem. 2020, 10, 314-317. [CrossRef] 
15. Feng, C.; Pedrero, Z.; Lima, L.; Olivares, S.; de la Rosa, D.; Berail, S.; Tessier, E.; Pannier, F.; Amouroux, D. Assessment of Hg contamination by a Chlor-Alkali Plant in riverine and coastal sites combining $\mathrm{Hg}$ speciation and isotopic signature (Sagua la Grande River, Cuba). J. Hazard. Mater. 2019, 371, 558-565. [CrossRef]

16. Muhammad, Y.A.; Sunaryono; Nenohai, A.; Mufti, N.; Taufiq, A. Adsorption Properties of Magnetic Sorbent Mn0. 25Fe2. 75O4@ SiO2 for Mercury Removal. Key Eng. Mater. 2020, 851, 197-204. [CrossRef]

17. Zhu, W.; Zhang, Y.; Wang, P.; Yang, Z.; Yasin, A.; Zhang, L. Preparation and Applications of Salt-Resistant Superabsorbent Poly (Acrylic Acid-Acrylamide/Fly Ash) Composite. Materials 2019, 12, 596. [CrossRef]

18. Xu, X.; Schierz, A.; Xu, N.; Cao, X. Comparison of the characteristics and mechanisms of Hg(II) sorption by biochars and activated carbon. J. Colloid Interface Sci. 2016, 463, 55-60. [CrossRef]

19. Srikhaow, A.; Butburee, T.; Pon-On, W.; Srikhirin, T.; Smith, S.M. Efficient Mercury Removal at Ultralow Metal Concentrations by Cysteine Functionalized Carbon-Coated Magnetite. Appl. Sci. 2020, 10, 262. [CrossRef]

20. Long, C.; Li, X.; Jiang, Z.; Zhang, P.; Feng, B. Adsorption-improved MoSe2 nanosheet by heteroatom doping and its application for simultaneous detection and removal of mercury (II). J. Hazard. Mater. 2021, 413, 125470-125487. [CrossRef]

21. Qasim, G.H.; Lee, S.; Lee, W.; Han, S. Reduction and removal of aqueous $\mathrm{Hg}(\mathrm{II})$ using indium-modified zero-valent iron particles. Appl. Catal. B Environ. 2020, 277, 119198-119218. [CrossRef]

22. Cheng, H.; Yu, J.; Zeng, K.; Hou, G. Application of Poly(Acrylic Acid)-Multiwalled Carbon Nanotube Composite for Enrichment of Rrace Hg(II). Plasma Process. Polym. 2013, 10, 931-937. [CrossRef]

23. Udomkitpanya, T.; Srikulkit, K. Properties of Poly(Lactic Acid) Blended with Natural Rubber-Graft- Poly(Acrylic Acid). Key Eng. Mater. 2020, 845, 45-50. [CrossRef]

24. Kolya, H.; Das, S.; Tripathy, T. Synthesis of Starch-g-Poly-(N-methylacrylamide-co-acrylic acid) and its application for the removal of mercury (II) from aqueous solution by adsorption. Eur. Polym. J. 2014, 58, 1-10. [CrossRef]

25. Kolya, H.; Tripathy, T. Hydroxyethyl Starch-g-Poly-(N,N-dimethylacrylamide-co-acrylic acid): An efficient dye removing agent. Eur. Polym. J. 2013, 49, 4265-4275. [CrossRef]

26. Perfetti, G.; Jansen, K.; Wildeboer, W.J.; Hee, P.V.; Meesters, G. Characterization of physical and viscoelastic properties of polymer films for coating applications under different temperature of drying and storage. Int. J. Pharm. 2010, 384, 109-119. [CrossRef]

27. Anirudhan, T.S.; Suchithra, P.S.; Divya, L. Adsorptive Potential of 2-Mercaptobenzimidazole-Immobilized Organophilic Hydrotalcite for Mercury(II) Ions from Aqueous Phase and Its Kinetic and Equilibrium Profiles. Water Air Soil Pollut. 2009, 196, 127-139. [CrossRef]

28. Yan, D.; Dong, H.; Ye, P.; Müller, A. Kinetic Analysis of "Living" Polymerization Processes Exhibiting Slow Equilibria. 6. Cationic Polymerization Involving Covalent Species, Ion Pairs, and Free Cations. Macromolecules 1996, 29, 8057-8063. [CrossRef]

29. Ling-Yun, Y.U.; Rui-Li, L.I.; Hai-Lun, W.U.; Zhang, S.F.; Lin, H. Selective Removal of $\mathrm{Cu}^{2+}$ Ion in Aqueous Solution by Poly (Acrylic Acid/Acrylamide) Hydrogel. Chin. J. Anal. Chem. 2020, 48, 20098-20106. [CrossRef]

30. Slaný, M.; Jankovič, L'.; Madejová, J. Structural characterization of organo-montmorillonites prepared from a series of primary alkylamines salts: Mid-IR and near-IR study. Appl. Clay Sci. 2019, 176, 11-20. [CrossRef]

31. Forouzandehdel, S.; Meskini, M.; Rami, M.R. Design and application of (Fe3O4)-GOTfOH based AgNPs doped starch/PEG-poly (acrylic acid) nanocomposite as the magnetic nanocatalyst and the wound dress. J. Mol. Struct. 2020, 1214, 128-142. [CrossRef]

32. Pereira, A.G.; Rodrigues, F.H.; Paulino, A.T.; Martins, A.F.; Fajardo, A.R. Recent advances on composite hydrogels designed for the remediation of dye-contaminated water and wastewater: A review. J. Clean. Prod. 2020, 284, 124703-124730. [CrossRef]

33. Cai, L.; Liu, C.; Fan, G.; Liu, C.; Sun, X. Preventing viral disease by ZnONPs through directly deactivating TMV and activating the plant immunity in Nicotiana benthamiana. Environ. Sci. Nano 2019, 6, 3653-3669. [CrossRef]

34. Awad, F.S.; AbouZied, K.M.; Bakry, A.M.; Abou El-Maaty, W.M.; El-Wakil, A.M.; El-Shall, M.S. Polyacrylonitrile modified partially reduced graphene oxide composites for the extraction of $\mathrm{Hg}(\mathrm{II})$ ions from polluted water. J. Mater. Sci. 2021, 56, 7982-7999. [CrossRef]

35. Elkhaleefa, A.; Ali, I.H.; Brima, E.I.; Shigidi, I.; Karama, B. Evaluation of the Adsorption Efficiency on the Removal of Lead(II) Ions from Aqueous Solutions Using Azadirachta indica Leaves as an Adsorbent. Processes 2021, 9, 559. [CrossRef]

36. Kuncoro, E.P.; Roussy, J.; Guibal, E. Mercury recovery by polymer-enhanced ultrafiltration: Comparison of chitosan and poly (ethylenimine) used as macroligand. Sep. Sci. Technol. 2005, 40, 659-684. [CrossRef]

37. Mi, Y.K.; Seo, H.; Tai, G.L. Removal of $\mathrm{Hg}(\mathrm{II})$ ions from aqueous solution by poly(allylamine-co-methacrylamide-codimethylthiourea)—ScienceDirect. J. Ind. Eng. Chem. 2020, 84, 82-86. [CrossRef]

38. Li, H.P.; Huang, Y.Y.; Yuan, J.W.; Yang, G.W.; Lv, H.Q.; Yang, S.J. Absorption of Hg (II) Form Aqueous Solution onto Double Crosslinked Amphoteric Cassava Starch Resin. Adv. Mater. Res. 2014, 886, 253-256. [CrossRef]

39. Chattoraj, D.K.; Im Ae, T.; Mitra, A. A generalized scale of free energy of excess adsorption of solute and absolute composition of the interfacial phase. Langmuir 2004, 20, 4903-4915. [CrossRef]

40. Zhang, M.; Yang, P.; Lan, G.; Liu, Y.; Cai, Q.; Xi, J. High crosslinked sodium carboxyl methylstarch- g -poly (acrylic acid- co -acrylamide) resin for heavy metal adsorption: Its characteristics and mechanisms. Environ. Sci. Pollut. Res. 2020, 27, 38617-38630. [CrossRef] 
41. Wang, X.; Wang, A. Adsorption characteristics of chitosan-g-poly (acrylic acid)/attapulgite hydrogel composite for Hg (II) ions from aqueous solution. Sep. Sci. Technol. 2010, 45, 2086-2094. [CrossRef]

42. Singh, V.; Singh, S.K.; Maurya, S. Microwave induced poly(acrylic acid) modification of Cassia javanica seed gum for efficient $\mathrm{Hg}$ (II) removal from solution. Chem. Eng. J. Lausanne 2010, 160, 129-137. [CrossRef] 